\title{
NOTES
}

\section{Molecular Weight Determination of Comb-Like Polymers}

\author{
Kenji Yokota, ${ }^{*}$ Tadamichi Hirabayashi, and Yoshihito INaI \\ Department of Materials Science \& Engineering, Nagoya Institute of Technology, \\ Gokiso-cho, Showa-ku, Nagoya 466, Japan
}

(Received June 21, 1993)

\begin{abstract}
KEY WORDS Comb-Like Polymer / Molecular Weight / Osmometry / Gel-Permeation Chromatography / Viscometry / Mark-Houwink-Sakurada Equation / Universal Calibration Curve /
\end{abstract}

In our previous papers, ${ }^{1-7}$ we have studied the synthesis, structure, and side-chain crystallization of various widely-spaced comb-like polymers. Their side-chains appear regularly on every 4,6 , or more main-chain atoms and crystallize as those of conventional comb-like polymers do. The molecular weights (MW's) of these comb-like polymers were determined by gel-permeation chromatography (GPC) calibrating by polystyrene (PST) standards. The MW determination was carried out only to confirm that the polymer samples in question were of enough high MW.

In this note, the MW determination of a comb-like polymer was carried out by GPC and by membrane osmometry. It was found that the MW by GPC is smaller than by osmometry. The universal calibration curve in GPC and the Mark-Houwink-Sakurada equation were also drawn. The comb-like polymer studied was a conventional type, poly(octadecyl methacrylate) (POMA). Therefore the comb-like polymer of interest is a regularly short-branched polymer and not a few randomly long-branched polymer. GPC of the latter polymer has been studied in order to determine the number of branchings. ${ }^{8}$

\section{EXPERIMENTAL}

\section{Materials}

The synthesis and purification of octadecyl methacrylate monomer (OMA) were already described. ${ }^{1}$ A tert-butyllithium solution in heptane $\left(1.7 \mathrm{moll}^{-1}\right)$ was available from Aldrich Chemicals, Japan. Triethylaluminum obtained from Ethyl Corp. was distilled and used as a toluene solution $\left(4.0 \mathrm{moll}^{-1}\right)$. PST standards were obtained from Tosoh Corp. Sample symbols, number-average MW $\left(M_{n}\right)$, weight-average to number-average MW ratio $\left(M_{w}{ }^{\prime} M_{n}\right)$ given by the supplier are as follows: A-5000, $6.15 \times 10^{3}, 1.04 ; \mathrm{F}-1,9.90 \times 10^{3}, 1.02$; F-2, $1.70 \times 10^{4}, 1.02 ; \mathrm{F}-4,4.26 \times 10^{4}, 1.01$; and F-10, $9.70 \times 10^{4}, 1.02$. Other reagents were commercially available.

\section{Polymer Preparation}

POMA samples were prepared by an anionic initiator in toluene. The initiator was a combination of tert-butylithium and triethylaluminum developed by Hatada et al. ${ }^{9}$ to synthesize a monodisperse and highly syndiotactic poly(methyl methacrylate) (PMMA). A typical polymerization experiment is as follows: In an ice-cooled $100 \mathrm{ml}$ cylindrical reaction vessel containing a small volume of toluene, the triethyl-aluminum $(3.0 \mathrm{mmol})$ solution, the tert-butyllithium $(1.0 \mathrm{mmol})$ solution, and 
OMA $(15 \mathrm{mmol})$ in toluene (total solvent volume was $60 \mathrm{ml}$ ) was mixed and stirred at $273 \mathrm{~K}$ for $24 \mathrm{~h}$. Then the polymerization was stopped by adding a small volume of methanol containing $1 \%$ hydrochloric acid. The product was precipitated in a large volume of methanol, reprecipitated three times by chloroform and methanol, and freeze-dried in vacuo. POMA was obtained in $63 \%$ yield. Since OMA monomer has a long alkyl group and easily freezes even in toluene solution, its polymerization could not be conducted at a low temperature as in the literature for MMA $(195 \mathrm{~K})^{9}$ and had to be done at $273 \mathrm{~K}$. This seems unfavorable for an ideal living polymerization, and, as a result, some POMA samples showed a GPC peak with a small tail. In such cases, the crude polymer was fractionated by a temperature-lowering method in chloroform-methanol solution to obtain a sample of smaller $M_{w} / M_{n}$.

\section{Measurements}

The MW's of POMA comb-like polymers were determined by means of osmometry, GPC, and viscometry. A Hewlett-Packard High Speed Membrane Osmometer Model 501 with S-08 membrane was used for the osmometry. The osmotic pressures $(\pi)$ at $310 \mathrm{~K}$ were determined usually at 5 polymer concentrations $(c)$ in toluene and the $\pi / c$ values were extrapolated to $c=0$. GPC was de- termined in tetrahydrofuran (THF) at $313 \mathrm{~K}$ on a Tosoh HLC 803D chromatograph with GMX-, G1000-, G2000-, and G4000-HXL columns in series. Chromatograms were calibrated by the PST standards to calculate $M_{n}$ and $M_{w}$. The THF flow rate was $1 \mathrm{ml}$ $\min ^{-1}$. Solution viscosities were determined also in THF at $313 \mathrm{~K}$ at 4 polymer concentrations by using an Ubbelohde viscometer and expressed in terms of intrinsic viscosities $[\eta]$.

\section{RESULTS AND DISCUSSION}

Table I summarizes the POMA preparation and the polymer MW determination. Their $M_{n}$ values by osmometry are in the range from $1 \times 10^{4}$ to $65 \times 10^{4}$. The $M_{w} / M_{n}$ values by GPC are found between 1.1 and 1.8. Apparently the monomer-to-initiator ratios in feed are not related to the $\mathrm{MW}$, and the $\mathrm{MW}$ distributions of POMA are broader than those of PMMA by the same initiator. ${ }^{9}$ The syndiotactic diad probability $P_{\mathrm{r}}$ of POMA is about 0.85 that is smaller than that of PMMA $\left(P_{\mathrm{r}}=1\right)$. Such poor results in case of POMA preparation may come from the presence of a long alkyl group in this monomer and the higher polymerization temperature as mentioned above but the polymer samples obtained are considered enough useful for the present study.

Figure 1 illustrates the relationship of MW's

Table I. Preparation of POMA's and their molecular weight parameters

\begin{tabular}{|c|c|c|c|c|c|c|c|c|}
\hline \multirow{2}{*}{ Run } & \multirow{2}{*}{ OMA } & \multirow{2}{*}{$\frac{t-\mathrm{BuLi}}{\mathrm{mmol}}$} & \multirow{2}{*}{$\frac{\mathrm{Et}_{3} \mathrm{Al}}{\mathrm{mmol}}$} & \multirow{2}{*}{ Toluene } & \multirow{2}{*}{$\frac{\text { Yield }}{\%}$} & \multicolumn{2}{|c|}{$M_{n} \times 10^{-4}$} & \multirow{2}{*}{$\begin{array}{c}M_{w} / M_{n} \\
\text { GPC }\end{array}$} \\
\hline & & & & & & Osmometry & GPC & \\
\hline 1 & 15 & 1.0 & 3.0 & 60 & $63^{a}$ & 1.02 & 0.899 & 1.19 \\
\hline 2 & 15 & 0.5 & 1.5 & 60 & $87^{a}$ & 1.19 & 0.993 & 1.14 \\
\hline 3 & 50 & 0.17 & 0.51 & 60 & $24^{\mathrm{b}}$ & 3.17 & 2.07 & 1.18 \\
\hline 4 & 15 & 0.1 & 0.5 & 50 & $86^{\mathrm{a}}$ & 3.57 & 2.47 & 1.40 \\
\hline 5 & 25 & 0.17 & 0.51 & 60 & $25^{\mathrm{b}}$ & 5.34 & 3.40 & 1.21 \\
\hline 6 & 20 & 0.34 & 1.0 & 50 & $35^{\mathrm{b}}$ & 7.50 & 5.01 & 1.21 \\
\hline 7 & 22 & 0.026 & 0.13 & 60 & $13^{\mathrm{b}}$ & 65.2 & 19.6 & 1.81 \\
\hline
\end{tabular}

\footnotetext{
a Polymer yield is referred to crude polymers.

b Polymer yield is referred to fractionated polymers.
} 


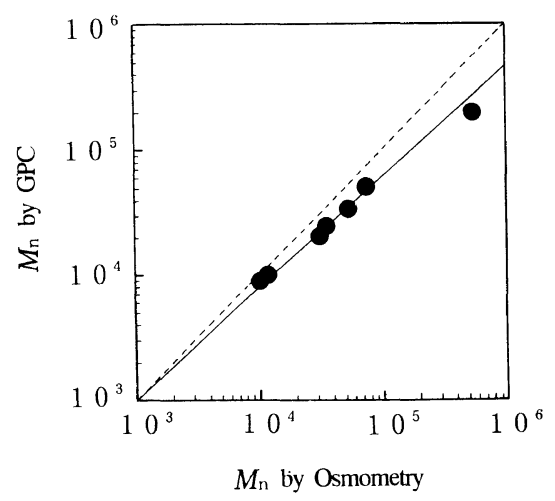

Figure 1. MW relationship of POMA comb-like polymers between determined by osmometry and by GPC.

Table II. Intrinsic viscosities of polymers ${ }^{a}$

\begin{tabular}{ccccc}
\hline \multicolumn{2}{c}{ PST } & & \multicolumn{2}{c}{ POMA } \\
\cline { 1 - 2 } Sample & {$[\eta]$} & & Run & {$[\eta]$} \\
\cline { 2 - 2 } & $\mathrm{dlg}^{-1}$ & & & $\mathrm{dl} \mathrm{g}^{-1}$ \\
\hline A-5000 & 0.068 & & 1 & 0.055 \\
F-1 & 0.093 & & 2 & 0.066 \\
F-2 & 0.137 & & 3 & 0.116 \\
F-4 & 0.263 & & 4 & 0.130 \\
F-10 & 0.464 & & 5 & 0.152 \\
& & 6 & 0.154 \\
& & 7 & 0.618
\end{tabular}

a Determined in $\mathrm{THF}$ at $313 \mathrm{~K}$.

of POMA determined by osmometry and by GPC. Each MW determined by GPC is smaller than that determined by osmometry. In view of the size exclusion mechanism for $\mathrm{GPC}^{10}$, this result demonstrates that the comb-like polymer of a given MW exists in a less expanded form than PST of the same MW in THF at $313 \mathrm{~K}$, and should be ascribed to the aggregating tendency of the long alkyl side-chains of the comb-like polymer in solution.

Table II shows the intrinsic viscosities for PST and POMA under the same conditions with GPC. The products of $[\eta]$ and $M_{n}$ by osmometry are plotted in Figure 2 against the retention volume $V e$ in GPC. Both data for

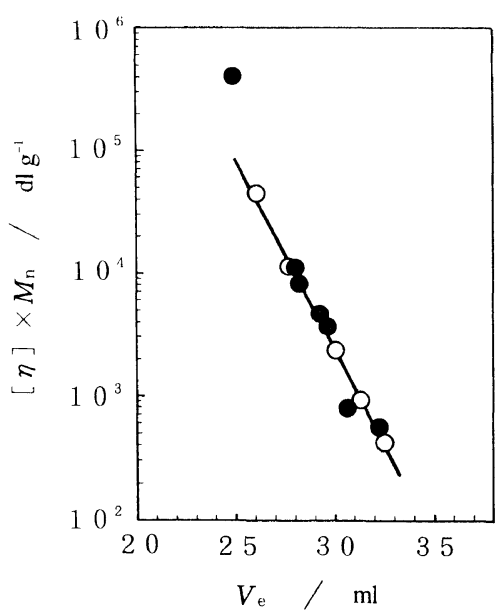

Figure 2. A plot of $[\eta] \times M_{n}$ against the retention volume of THF in GPC: $O$, PST; 0 , POMA.

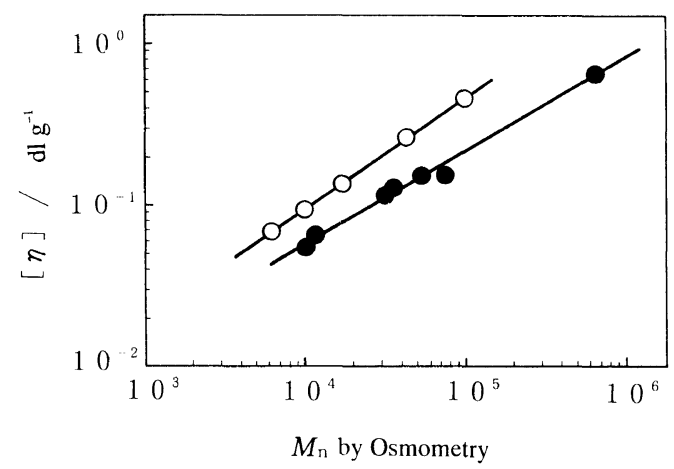

Figure 3. Plots of $[\eta]$ against $M_{n}$ for PST and for POMA: O, PST; O, POMA.

PST and for POMA make a line which is known as an universal calibration curve in GPC. ${ }^{11}$

Figure 3 plots the intrinsic viscosities $[\eta]$ against the $M_{n}$ for PST standards and for POMA. From these plots, the $K$ and $\alpha$ parameters in the Mark-Houwink-Sakurada equation are calculated and given in Table III; $a=0.69$ for PST and $\mathrm{a}=0.58$ for POMA. This result is a reflection of the observation in Figure 1. Table III also collects some $K$ and a parameters from literatures. ${ }^{12-16}$ In these literature data, any significant difference between $\alpha$ for PST and for POMA is not found. The inconsistent determination temperature 
Table III. Parameters in Mark-Houwink-Sakurada equation in THF

\begin{tabular}{|c|c|c|c|c|c|}
\hline \multirow{2}{*}{ Polymer } & \multirow{2}{*}{$\frac{\text { Temp. }}{\mathbf{K}}$} & \multirow{2}{*}{$\frac{K \times 10^{4}}{\mathrm{dl} \mathrm{g}^{-1}}$} & \multirow{2}{*}{$\alpha$} & \multirow{2}{*}{$\begin{array}{c}\text { MW range } \\
\times 10^{-4}\end{array}$} & \multirow{2}{*}{ Literature } \\
\hline & & & & & \\
\hline PST & 313 & 2.3 & 0.69 & $0.6-9.7$ & Present paper \\
\hline PST & 298 & 1.10 & 0.725 & $1-100$ & Lit. $^{13}$ \\
\hline PST & 298 & 1.4 & 0.70 & - & Lit. $^{14}$ \\
\hline POMA & 313 & 1.5 & 0.58 & $1.0-65.2$ & Present paper \\
\hline POMA & 303 & 0.25 & 0.75 & $20-170$ & Lit. $^{15}$ \\
\hline POMA & 303 & 0.9 & 0.67 & $1.5-94$ & Lit. ${ }^{16}$ \\
\hline
\end{tabular}

might partly be responsible for it. On the contrary, a difference in $\alpha$ is found between them in the present note. The characteristic of POMA in polar THF solvient when compared to PST that the comb-like polymer has nonpolar and aggregating long alkyl sidechains is more prominent at the determination temperature of $313 \mathrm{~K}$ in this note.

Acknowledgments. The authors thank Prof. T. Kato of Mie University for his helpful discussion. They also thank Messrs. Y. Komatsu, O. Kurata, M. Fujita, M. Kawamura, and S. Tsutsumi for their technical assistance.

\section{REFERENCES}

1. K. Yokota, T. Kougo, and T. Hirabayashi, Polym. J., 15, 891 (1983).

2. K. Yokota and T. Hirabayashi, Polym. J., 17, 991 (1985).

3. K. Yokota and T. Hirabayashi, Polym. J., 18, 177 (1986).

4. T. Hirabayashi and K. Yokota, Polym. J., 19, 1115 (1987).

5. T. Hirabayashi, T. Kikuta, K. Kasabou, and K. Yokota, Polym. J., 20, 693 (1988).

6. T. Hirabayashi, K. Kasabou, and K. Yokota, Polym.

\section{J., 20, 911 (1988).}

7. K. Yokota, Masao Ohtubo, T. Hirabayashi, and Y. Inai, Polym. J., to be published.

8. T. Takeuchi and S. Mori, "Geru Paamieishon Kuromatogurafii (Gel Permeation Chromatography)," Maruzen Co., Tokyo, 1976, Chapter 6.

9. T. Kitayama, T. Shinozaki, E. Masuda, M. Yamamoto, and K. Hatada, Polym. Bull., 20, 505 (1988).

10. T. Takeuchi and S. Mori, "Geru Paamieishon Kuromatogurafii (Gel Permeation Chromatography)," Marugzen Co., Tokyo, 1976, Chapter 1

11. The universal calibration curve is usually drawn by plotting $[\eta] \times M_{v}$ on the ordinate. In Figure 2, we plotted $[\eta] \times M_{n}$ instead. Even when we plotted $[\eta] \times M_{w}$ (multiplying $[\eta] \times M_{n}$ by $M_{w} / M_{n}$ ), we could find the same calibration curve because our polymer samples were of narrow MW distribution. Around the highest MW POMA, no data for PST standards are available but one may still draw the same conclusion.

12. J. Brandrup and E. H. Immergut, Ed., "Polymer Handbook," 3rd ed, Wiley-Interscience, New York, N.Y., 1989, p VII-15.

13. A. L. Spatorico and B. Coulter, J. Polym. Sci., Polym. Phys. Ed., 11, 1139 (1973).

14. C. Strazielle, H. Benoit, and O. Vogl, Eur. Polym. J., 14, 331 (1983).

15. J. G. Fee, W. S. Port, and L. P. Whitnauer, J. Polym. Sci., 33, 95 (1958).

16. X. Zhongde, S. Mingshi, N. Hadjichristidis, and L. J. Fetters, Macromolecules, 14, 1591 (1981). 